\section{Military Technical College Kobry El-Kobbah, Cairo, Egypt}

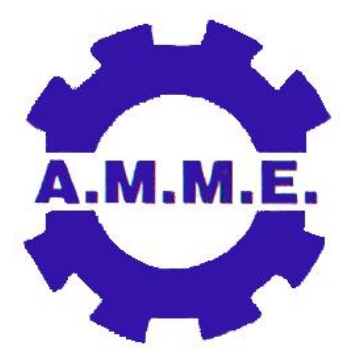

14th International Conference on

Applied Mechanics and

Mechanical Engineering.

\title{
Frequency Response of 10 Degrees of Freedom Model For Vehicle Dynamics
}

\author{
By \\ Nasser Abdel-aziem * \\ Galal Hassan **
}

\section{Abstract:}

A mathematical model for a full vehicle dynamic system of 10 degrees of freedom is derived using Lagrange's equation. The model is used to simulate the vibration response of the vehicle according to a road having sinusoidal disturbance for vehicle speed up to $200 \mathrm{~km} / \mathrm{hr}$.

All the vehicle natural frequencies are evaluated. The vibration level of the driver and passengers are computed at different vehicle speeds and compared with the recommended values according to ISO 2631 standards.

\section{Keywords:}

Vehicle dynamics - mathematical model - frequency response - ISO 2631 
Emeritus professor, MDP Department Faculty of Engineering, Cairo University, Giza, Egypt

\section{Introduction:}

In 1769 Nicholas Cugnot (1725-1804), built a three-wheeled steam-driven vehicle [1]. From that time vehicle power, speed and high performance increased tremendously. This required the complete understanding of vehicle dynamics.

The studying of vibration effect on the occupational performance and health is very important. Effects such as annoyance, discomfort, back pain and hearing loss are results of human exposed for vibration. There is several methods for analysis and evaluation of human exposure to whole-body vibration (WBV). The international standard (ISO 2631-1) and British standard (BS 6841) are the regular methods used for evaluation and assessment of WBV based on acceleration [2].

Vehicle represents a complex structural system with many degrees of freedom [3]. Modification and improvement in vehicle specification are required to achieve high performance and quality especially for comfort and safety of passengers. Suspension systems are used to isolate the vehicle chassis against road disturbance transmission and to control body roll about $\mathrm{x}$-axis to allow a minimum camber angle alteration in case of vehicle acceleration, braking and vehicle driven in a curve or in case of rough road. Chassis suspension system filters these vibrations by absorbing a part of the elastic energy and kinetic energy [4].

Researches found that a 3-D vehicle model may be including multi DOF, although 7 degrees of freedom are sufficient for general passenger cars [5]. Increasing the degrees of freedom of the mathematical model achieves more accuracy of the model analysis and more information otherwise omitted from a simple model and the system matrix become more complex.

Meanwhile, active control technology began to be adapted on practical vehicles. Active suspension, active anti-roll bar, active steering and active engine mounts were developed in the past 20 years. Many designs have since then been installed on practical vehicles. Integration of modern control theory into traditional vehicle technology has been a popular research area for example the application of fuzzy logic control system and non linear vehicle model [6].

The mathematical model derived in this work is linear. It is used in studying the bounce in $z$-axis, rolling about $x$-axis, pitching about $y$-axis of sprung mass, vibration of sprung and unsprung mass and completed by driver and passengers vibrations. The amplitude of vibration of driver and passengers at different vehicle speed is compared with the requirements of the international standards ISO 2631 part 1. 


\section{The Modeled Vehicle:}

1. A simplified physical model of the vehicle is shown in Fig.1

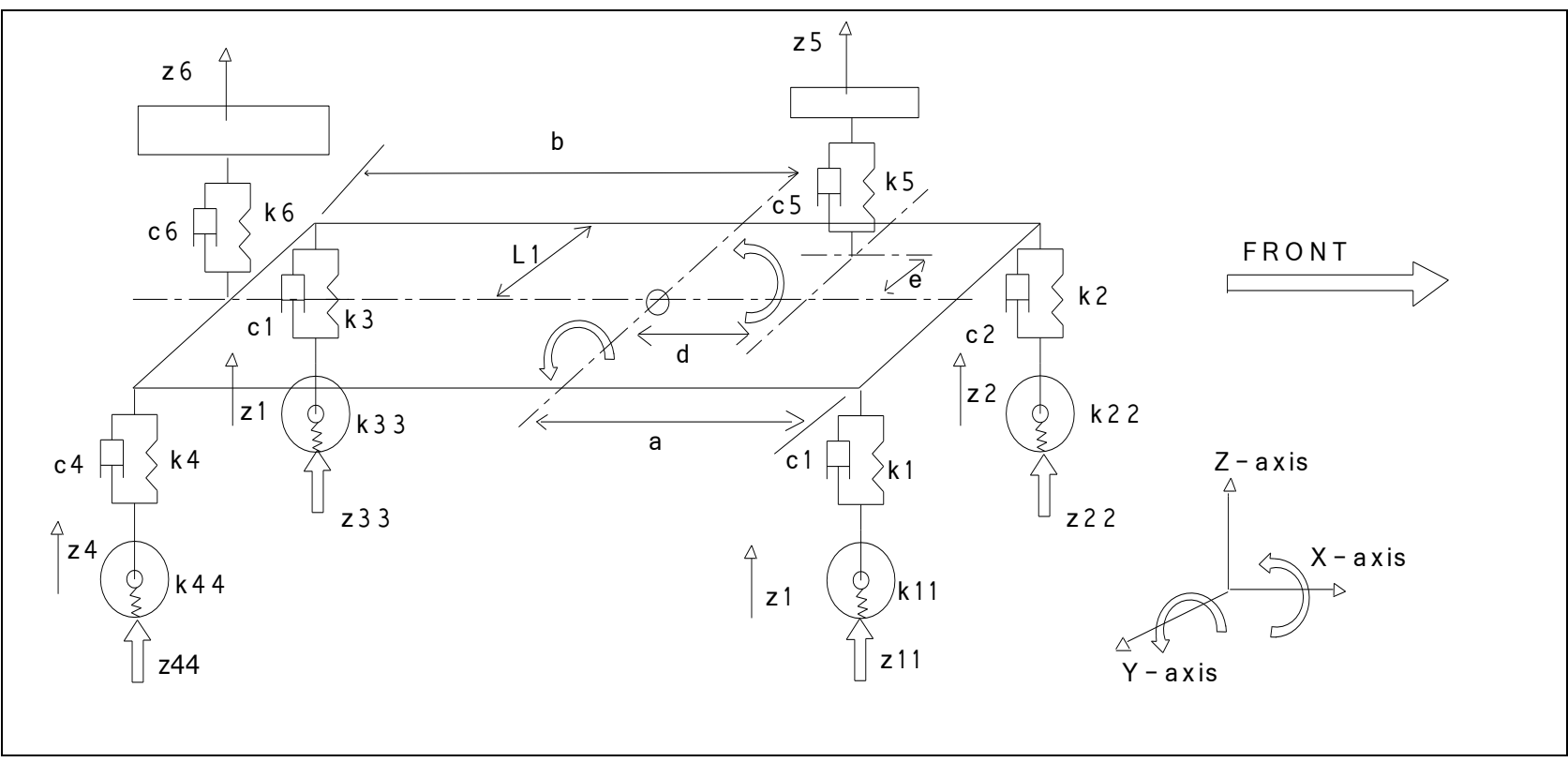

Figure (1): vehicle physical model

\section{System Description:}

There are 10 degrees of freedom for the vehicle system of Fig. (1) As follows:

1) Vehicles chassis vertical motion in Z-axis.

2) Vehicles chassis pitching (about $Y$-axis) $\left({ }^{\Theta}\right)$.

3) Vehicles chassis rolling (about $X$-axis) (Ø).

4) Vehicles chassis lateral motion ( $y$ ).

5) Driver bounce $\left(z_{5}\right)$ (vertical motion in Z-axis).

6) Passengers bounce $\left(z_{6}\right)$ (vertical motion in $Z$-axis).

7) Front right wheel bounce $\left(z_{1}\right)$.

8) Front left wheel bounce $\left(z_{2}\right)$.

9) Rear left wheel bounce $\left(z_{3}\right)$.

10)Rear right wheel bounce $\left(z_{4}\right)$.

The model is exited at wheels by motions $z_{11}, z_{22}, z_{33}$ and $z_{44}$ which results from the traveling of vehicle over the sinusoidal hump. 


\section{Vehicle Dynamics Simulation:}

\subsection{Vehicle simulation Parameters:}

The parameters of the vehicle used in this work are given in Table (1) [7].

Table (1): Dynamic system parameters

\begin{tabular}{|c|c|l|c|c|l|}
\hline Parameter & Value & \multicolumn{1}{|c|}{ Description } & Parameter & Value & \multicolumn{1}{|c|}{ Description } \\
\hline $\mathrm{M}_{1}(\mathrm{Kg})$ & 1100 & Vehicle sprung mass. & $\begin{array}{c}\mathrm{C}_{3}, \mathrm{C}_{4} \\
(\mathrm{Ns} / \mathrm{m})\end{array}$ & 2500 & $\begin{array}{l}\text { damping constant of rear } \\
\text { suspension dampers }\end{array}$ \\
\hline $\mathrm{m}_{1}, \mathrm{~m}_{2}(\mathrm{Kg})$ & 25 & $\begin{array}{l}\text { Unsprung mass of front } \\
\text { wheel. }\end{array}$ & $\mathrm{C}_{5}(\mathrm{Ns} / \mathrm{m})$ & 150 & Damping constant of driver seat. \\
\hline $\begin{array}{c}\mathrm{m}_{3}, \mathrm{~m}_{4} \\
(\mathrm{Kg})\end{array}$ & 45 & $\begin{array}{l}\text { Unsprung mass of rear } \\
\text { wheel. }\end{array}$ & $\mathrm{C}_{6}(\mathrm{Ns} / \mathrm{m})$ & 300 & Damping constant rear seat. \\
\hline $\mathrm{m}_{5}(\mathrm{Kg})$ & 90 & $\begin{array}{l}\text { Mass of driver and } \\
\text { seat. }\end{array}$ & $\begin{array}{c}\mathrm{k}_{11}, \mathrm{k}_{22} \\
(\mathrm{~N} / \mathrm{m})\end{array}$ & 250000 & Front tire stiffness constants. \\
\hline $\mathrm{m}_{6}(\mathrm{Kg})$ & 180 & $\begin{array}{l}\text { Mass of passenger and } \\
\text { rear seat. }\end{array}$ & $\mathrm{k}_{33}, \mathrm{k}_{44}$ & 250000 & Rear tire stiffness constants. \\
\hline $\mathrm{I}_{\mathrm{x}}\left(\mathrm{kg} \cdot \mathrm{m}^{2}\right)$ & 550 & $\begin{array}{l}\text { Moment of inertia of } \\
\text { sprung mass about } \mathrm{x} \\
\text { axis. }\end{array}$ & $\mathrm{k}_{1 \mathrm{t}}, \mathrm{k}_{2 \mathrm{t}}$ & 5250 & $\begin{array}{l}\text { Lateral stiff. of front suspension } \\
\text { spring }\end{array}$ \\
\hline $\mathrm{I}_{\mathrm{y}}\left(\mathrm{kg} \cdot \mathrm{m}^{2}\right)$ & 1848 & $\begin{array}{l}\text { Moment of inertia of } \\
\text { sprung mass about } \mathrm{y} \\
\text { axis. }\end{array}$ & $\mathrm{k}_{3 \mathrm{t}}, \mathrm{k}_{4 \mathrm{t}}$ & 5250 & $\begin{array}{l}\text { Lateral stiff. Of rear suspension } \\
\text { spring. }\end{array}$ \\
\hline $\mathrm{k}_{1}, \mathrm{k}_{2}(\mathrm{~N} / \mathrm{m})$ & 1500 & $\begin{array}{l}\text { Stiffness constant of } \\
\text { front suspension } \\
\text { spring. }\end{array}$ & $\mathrm{a}(\mathrm{mm})$ & 1200 & $\begin{array}{l}\text { The distance from front wheel } \\
\text { axis and C.G of vehicle. }\end{array}$ \\
\hline $\mathrm{k}_{3}, \mathrm{k}_{4}(\mathrm{~N} / \mathrm{m})$ & 1700 & $\begin{array}{l}\text { Stiffness constant of } \\
\text { rear suspension spring. }\end{array}$ & $\mathrm{b}(\mathrm{mm})$ & 1400 & $\begin{array}{l}\text { The distance from rear wheel } \\
\text { axis and C.G of vehicle. }\end{array}$ \\
\hline $\mathrm{k}_{5}(\mathrm{~N} / \mathrm{m})$ & 15000 & $\begin{array}{l}\text { Stiffness constant of } \\
\text { driver seat. }\end{array}$ & $\mathrm{L}_{1}(\mathrm{~mm})$ & 500 & $\begin{array}{l}\text { Lateral distance from wheels } \\
\text { and C.G of vehicle. }\end{array}$ \\
\hline $\mathrm{k}_{6}(\mathrm{~N} / \mathrm{m})$ & 30000 & $\begin{array}{l}\text { Stiffness constant of } \\
\text { passenger seat. }\end{array}$ & $\mathrm{e}(\mathrm{mm})$ & 300 & $\begin{array}{l}\text { The distance between front seat } \\
\text { C.G and X axis. }\end{array}$ \\
\hline $\begin{array}{c}\mathrm{C}_{1}, \mathrm{C}_{2} \\
(\mathrm{Ns} / \mathrm{m})\end{array}$ & 2500 & $\begin{array}{l}\text { Dam. const. of front } \\
\text { suspension dampers }\end{array}$ & $\mathrm{d}(\mathrm{mm})$ & 250 & $\begin{array}{l}\text { The distance between front seat } \\
\text { CG and Y axis. }\end{array}$ \\
\hline
\end{tabular}

The road disturbances are sinusoidal with the following values:

- Wave length $\left(L_{h}\right)$ equal 4.5 meter.

- Wave peak amplitude $(\mathrm{H})$ equal 0.05 meters.

\subsection{The Model Validation:}

A validation is investigated by using two different methods (central difference method and Runge-Kutta method) to solve the model as a different methods and comparison with published research are done.

\section{2 dynamic system simulations:}

A complete mathematical model of the vehicle with 10 DOF is derived using Lagrange's equation and used in previous time analysis work [8].

The MATLAB software program is used to solve the differential equations of motion by using the central difference method as a numerical integration technique $[8,9]$. The mathematical model is constructed by applying the Lagrange's equation to the system 
and writing the equations in matrix form. MATLAB is used to assign the system. The simulation analysis results of the system are given in table (2).

Table (2): system eigenvalues and natural frequencies

\begin{tabular}{|l|l|l|l|l|l|}
\hline Order & Eigenvalues & $\begin{array}{l}\text { Undamped } \\
\text { Natural } \\
\text { Frequency } \\
(\mathbf{r a d} / \mathbf{s})\end{array}$ & $\begin{array}{l}\text { Undamped } \\
\text { Natural } \\
\text { Frequency } \\
(\mathbf{H z})\end{array}$ & $\begin{array}{l}\text { Damped } \\
\text { Natural } \\
\text { Frequency } \\
(\mathbf{r a d} / \mathbf{s})\end{array}$ & $\begin{array}{l}\text { Damped } \\
\text { Natural } \\
\text { Frequency } \\
\text { (Hz) }\end{array}$ \\
\hline$(1)$ & $-50.1732+85.2545 \mathrm{i}$ & 4.3693 & 0.695 & 4.369 & 0.6954 \\
\hline$(2)$ & $-50.0541+88.7848 \mathrm{i}$ & 5.1761 & 0.823 & 5.286 & 0.841 \\
\hline$(3)$ & $-27.9950+67.9251 \mathrm{i}$ & 6.4079 & 1.019 & 6.92 & 1.1015 \\
\hline$(4)$ & $-27.9130+70.9737 \mathrm{i}$ & 6.7125 & 1.068 & 7.0288 & 1.118 \\
\hline$(5)$ & $-2.9204+15.1975 \mathrm{i}$ & 13.4955 & 2.147 & 13.344 & 2.123 \\
\hline$(6)$ & $-1.2065+13.2896 \mathrm{i}$ & 15.8647 & 2.524 & 15.4755 & 2.463 \\
\hline$(7)$ & $-3.7684+5.9332 \mathrm{i}$ & 77.0346 & 12.26 & 73.468 & 11.692 \\
\hline$(8)$ & $-2.9495+6.2609 \mathrm{i}$ & 77.0564 & 12.26 & 76.265 & 12.138 \\
\hline$(9)$ & $-2.0384+4.8773 \mathrm{i}$ & 102.96 & 16.38 & 98.92 & 15.744 \\
\hline$(10)$ & $0.0000+4.3693 \mathrm{i}$ & 102.97 & 16.38 & 101.922 & 16.221 \\
\hline
\end{tabular}

\subsection{Frequency Response:}

The system is subjected to harmonic excitation in form of displacement of vehicle wheels as a result of a road sinusoidal disturbance which effect on vehicle wheels.

The responses of the system are shown in figure (2) to figure (10).
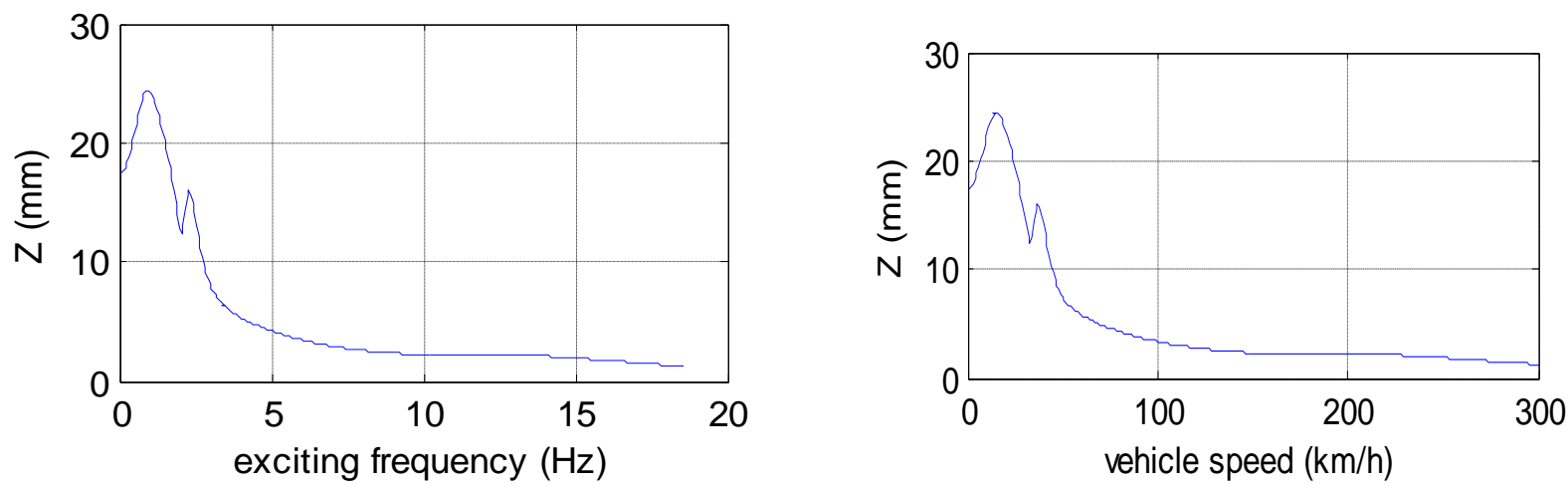

Figure (2): Vehicles chassis bounce (Z)
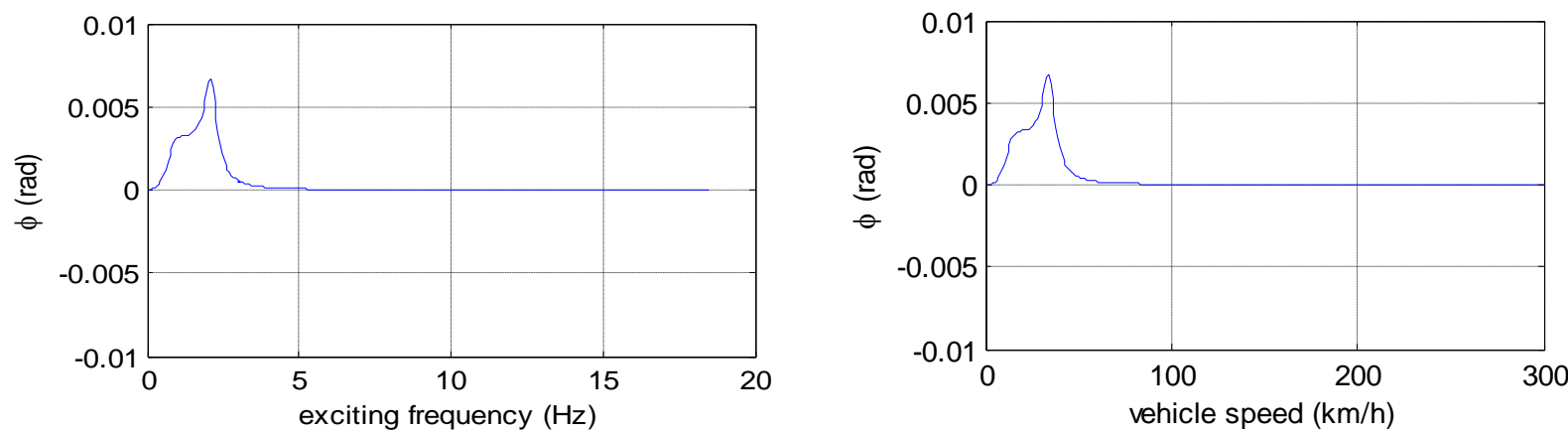

Figure (3): Vehicles chassis rolling (about X-axis) (Ø). 

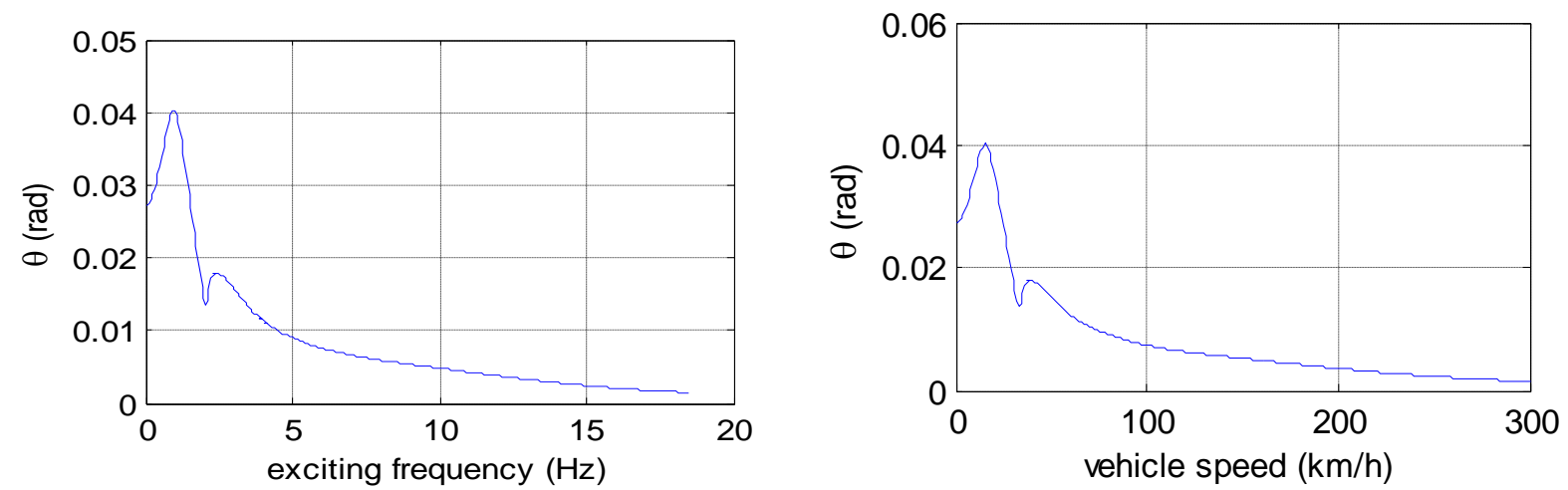

Figure (4): Vehicles chassis pitching (about $Y$-axis) $(\Theta)$.
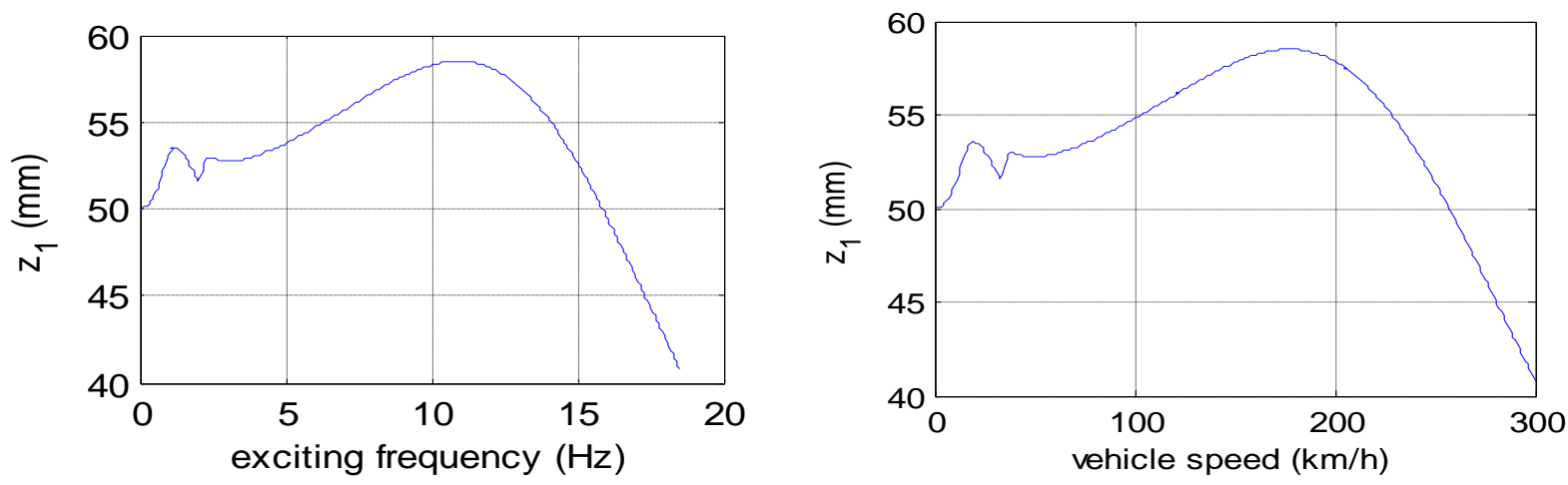

Figure (5): Front right wheel bounce $\left(Z_{1}\right)$.
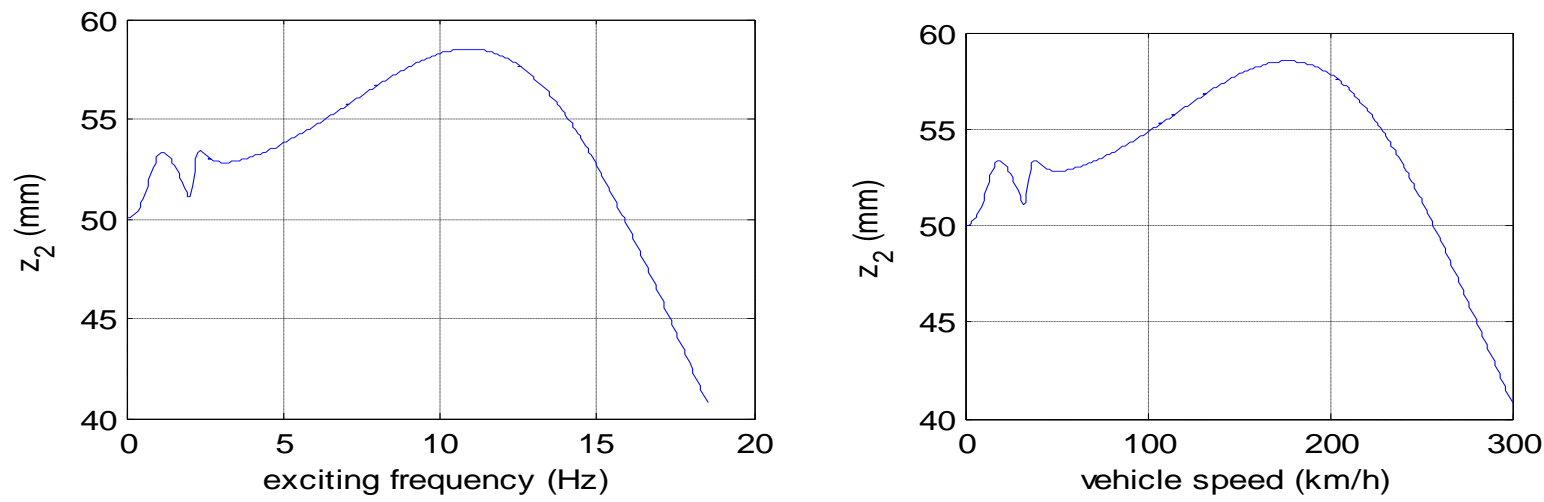

Figure (6): Front left wheel bounce $\left(Z_{2}\right)$.
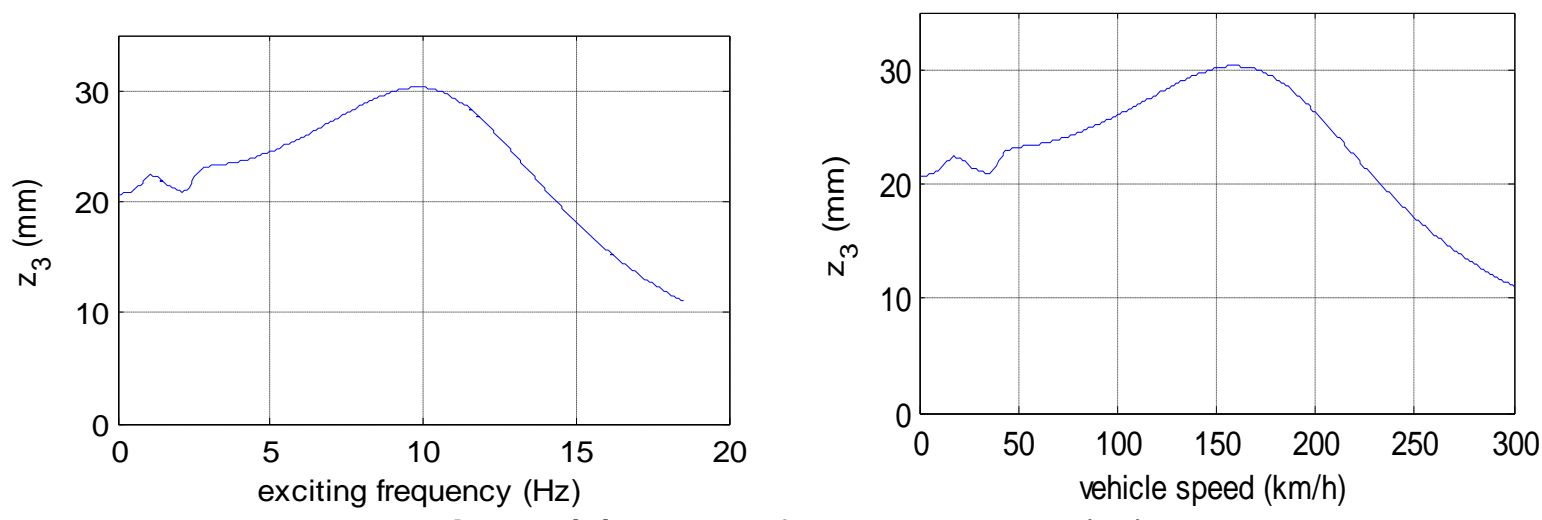

Figure (7): Rear left wheel bounce $\left(Z_{3}\right)$. 

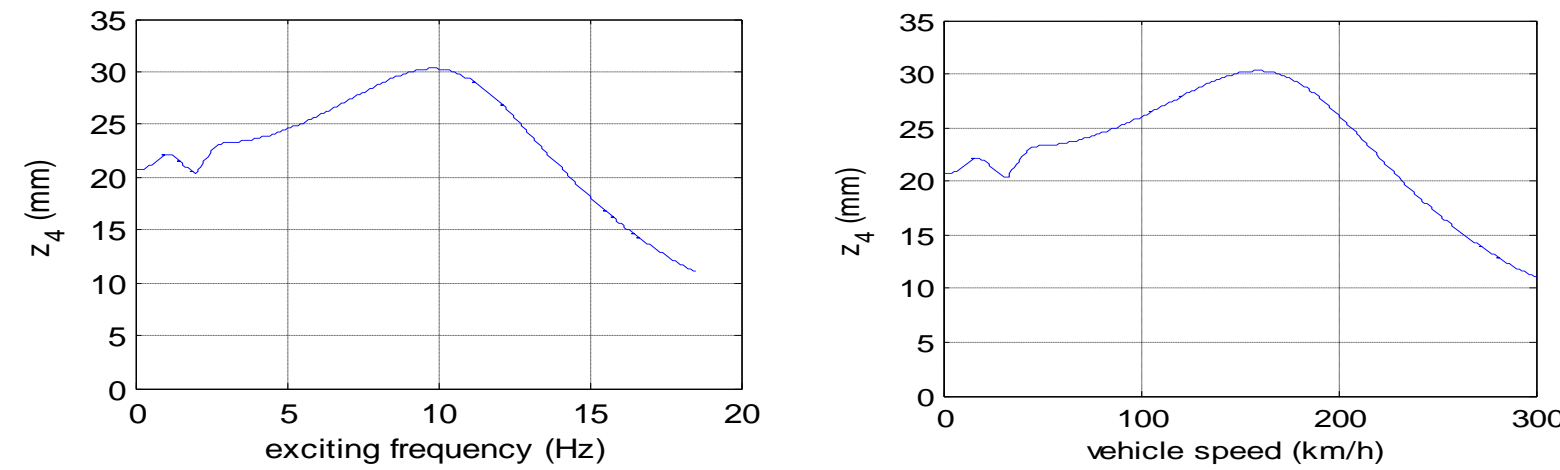

Figure (8): Rear right wheel bounce (Z4).
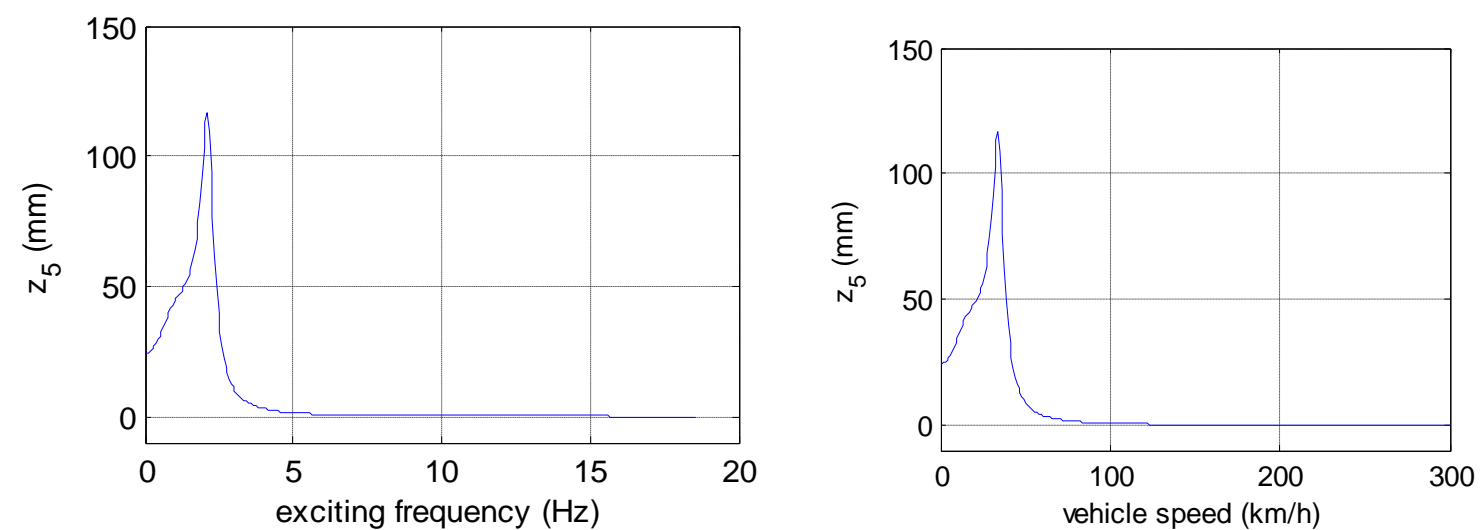

Figure (9): Driver bounces $\left(Z_{5}\right)$ vertical motion in Z-axis.
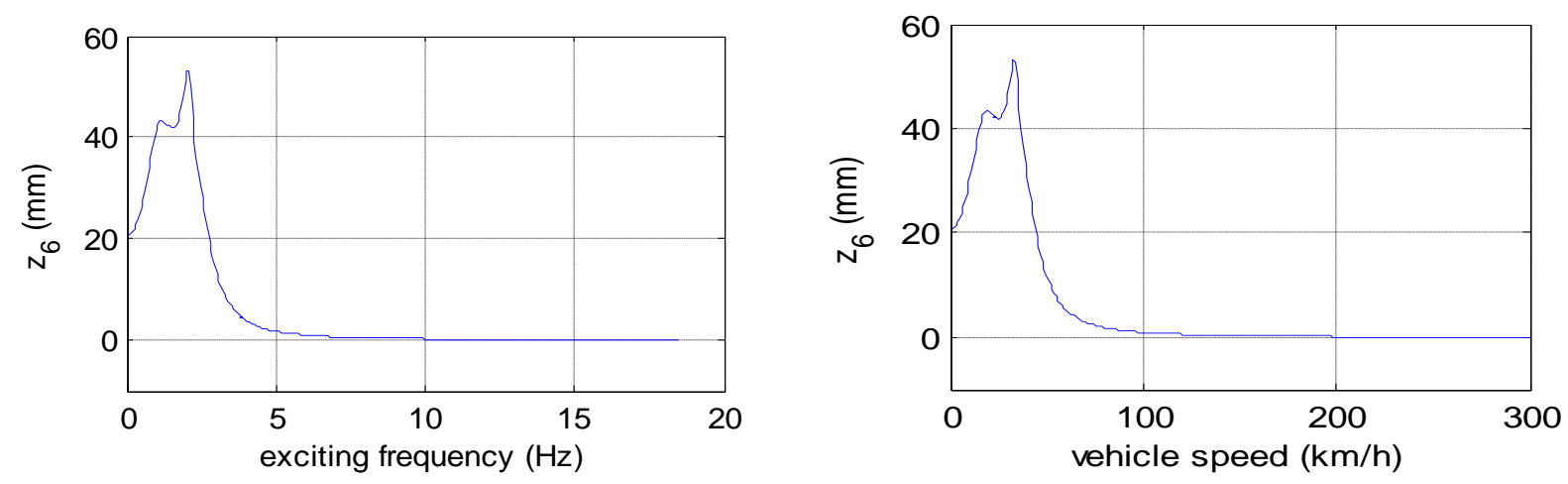

Figure (10): Passengers bounce $\left(Z_{6}\right)$ vertical motion in $Z$-axis.

\subsection{Statistical data for frequency response of the system:}

\begin{tabular}{|l|l|l|l|l|l|}
\hline Motion & Description & Min & Max & Mean & Range \\
\hline$z(\mathrm{~mm})$ & Bounce of chassis z-axis & 1.257 & 24.38 & 5.101 & 23.12 \\
\hline $\mathrm{y}(\mathrm{mm})$ & chassis lateral motion & 0 & 0 & 0 & 0 \\
\hline$\varnothing(\mathrm{rad})$ & chassis rolling (about X-axis) & $1.4 \mathrm{e}^{-006}$ & 0.00667 & 0.000455 & 0.00667 \\
\hline$\Theta(\mathrm{rad})$ & chassis pitching (about Y-axis) & 0.0014 & 0.040 & 0.0008 & 0.0386 \\
\hline$z_{1}(\mathrm{~mm})$ & Bounce of right front wheel in z-axis & 40.78 & 58.5 & 53.61 & 17.72 \\
\hline$z_{2}(\mathrm{~mm})$ & Bounce of left front wheel in z-axis & 40.78 & 58.5 & 53.61 & 17.72 \\
\hline$z_{3}(\mathrm{~mm})$ & Bounce of right rear wheel in z-axis & 11.02 & 30.29 & 23.08 & 19.26 \\
\hline$z_{4}(\mathrm{~mm})$ & Bounce of left rear wheel in z-axis & 11.03 & 30.29 & 23.08 & 19.27 \\
\hline$z_{5}(\mathrm{~mm})$ & Bounce of driver in z-axis & 0.030 & 116.8 & 8.375 & 116.8 \\
\hline$z_{6}(\mathrm{~mm})$ & Bounce of passengers in z-axis & 0.017 & 53.31 & 6.331 & 53.29 \\
\hline
\end{tabular}




\section{Whole body vibration:}

The whole body vibration of human body is transmitted to the body through the supporting surfaces such as the feet, buttocks or back. There are various sources of whole body vibration such as standing on a vibrating platform, floor surface, driving, and construction, manufacturing, and transportation vehicles [10].

The effects of whole body vibration exposure for human may be bio-dynamics, psychological, physiological or pathological [11]. The level of effects depends on the frequency, acceleration and the time of exposure (long-term or short term exposure).

\section{The International Standards: ISO 2631}

ISO 2631 was first published in 1974, with the purpose of giving numerical values for limits of exposure for vibrations transmitted from solid surfaces to the human body in the frequency range 1 to $80 \mathrm{~Hz}$. The standard was republished in 1978, 1982, 1985 and 1997, with major revisions along the way. The current version of ISO 2631, entitled "Mechanical vibration and shock - Evaluation of human exposure to whole-body vibration" consists of four parts (labeled 2631-1, 2631-2, 2631-4 and 2631-5). The part that is relevant to the current paper is 2631-1, which is called "General Requirements." ISO 2631-1:1997 provides a more quantitative guide on the effects of vibration on health and comfort [12].

\subsection{Measuring the Risk from Whole Body Vibration:}

Vibration is measured in three directions; longitudinal (buttocks to head, $\mathrm{a}_{\mathrm{z}}$ ), and two transverse directions (chest to back, $a_{x}$, and right to left side, $a_{y}$ ) as shown in figure (11.a). When the weighted acceleration $\left(a_{x}, a_{y}, a_{z}\right)$ are combined, the resultant acceleration is the vector sum. This amount of the vector sum can be used primarily for comparison with the vector sum of other motions. In this paper, analysis and assessment are done for vertical direction (z-direction). The limits based on the period of expose from 1 min until $24 \mathrm{hr}$ of ISO 2631-1 are shown in figure (11.b).

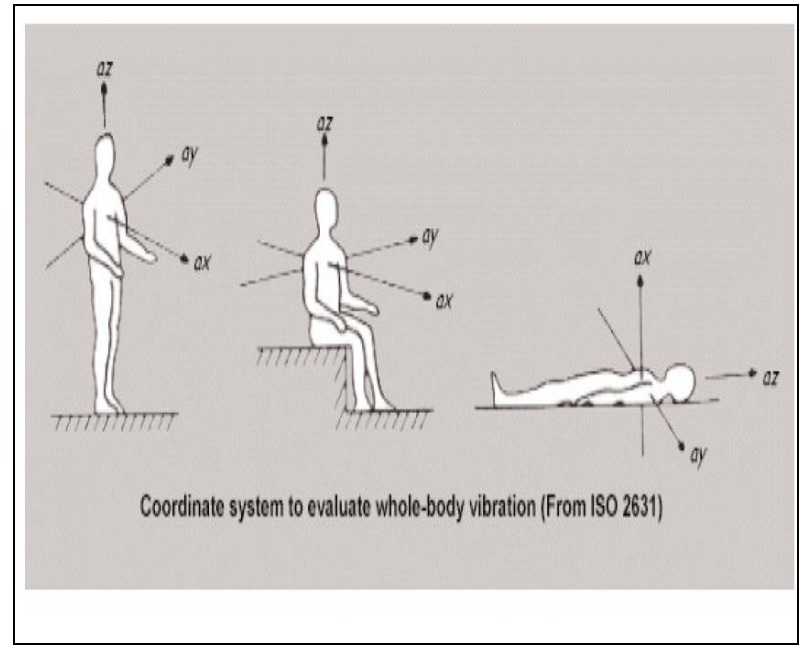

Figure (11.a): ISO2631 Coordinate system.

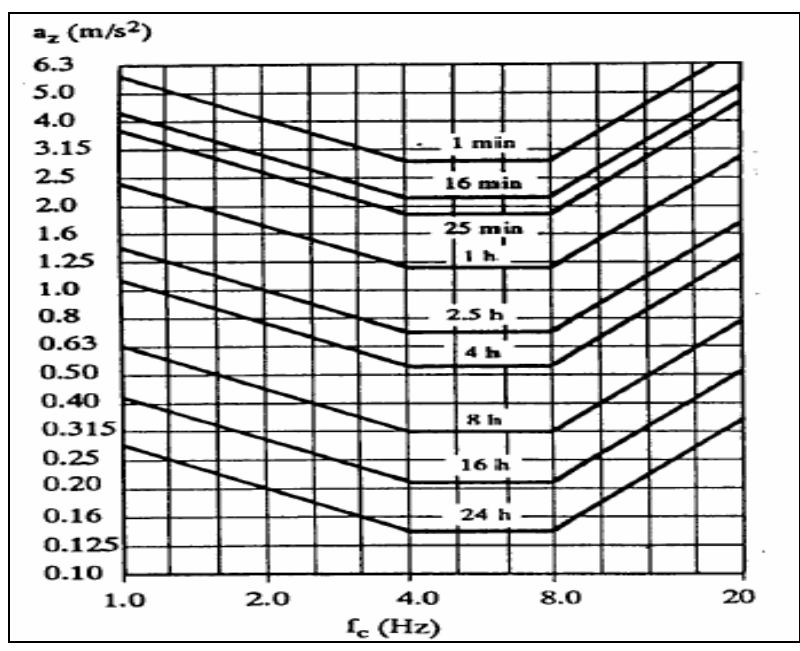

Figure (11.b): ISO2631 Limits 


\subsection{ISO. 2631 Limits and Frequency Simulation for Driver and Passengers:}

The compression between the passengers and driver bounces acceleration in root main square form with respect to the ISO 2631 standards are shown in figures (12\&13). The passengers vibration are accepted for all the exposure limits except for the 24 hours limit not accepted when the vehicle speed about $30 \mathrm{~km} / \mathrm{hr}$.

The driver vibration are accepted for all the exposure limits except for the 16 hours limit not accepted when the vehicle speed about $30 \mathrm{~km} / \mathrm{hr}$ and also for 24 limit not accepted when vehicle speed between 25 and $40 \mathrm{~km} / \mathrm{hr}$ as shown in figures $(9,10,12,13)$.

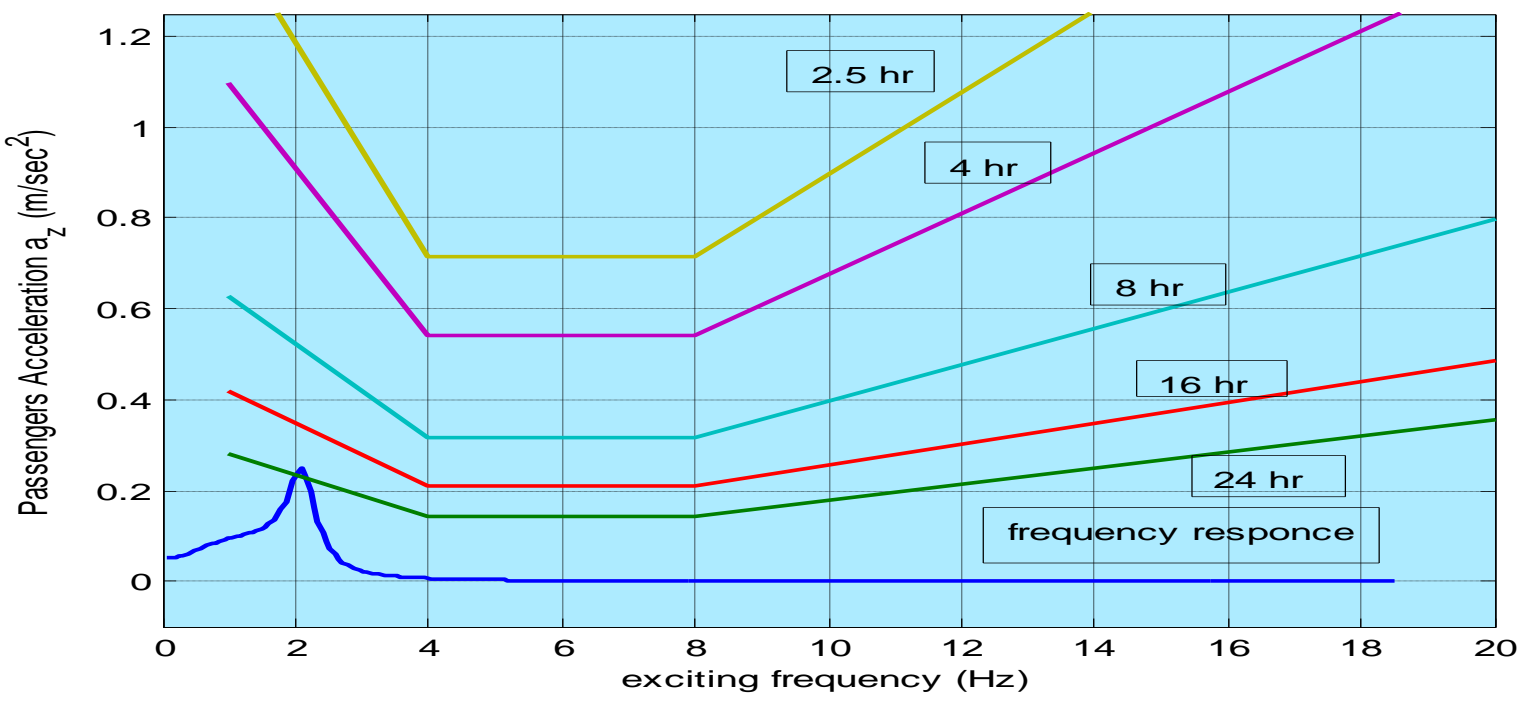

Figure (12): Passengers bounce $\left(Z_{6}\right)$ acceleration rms and ISO2631 limits.

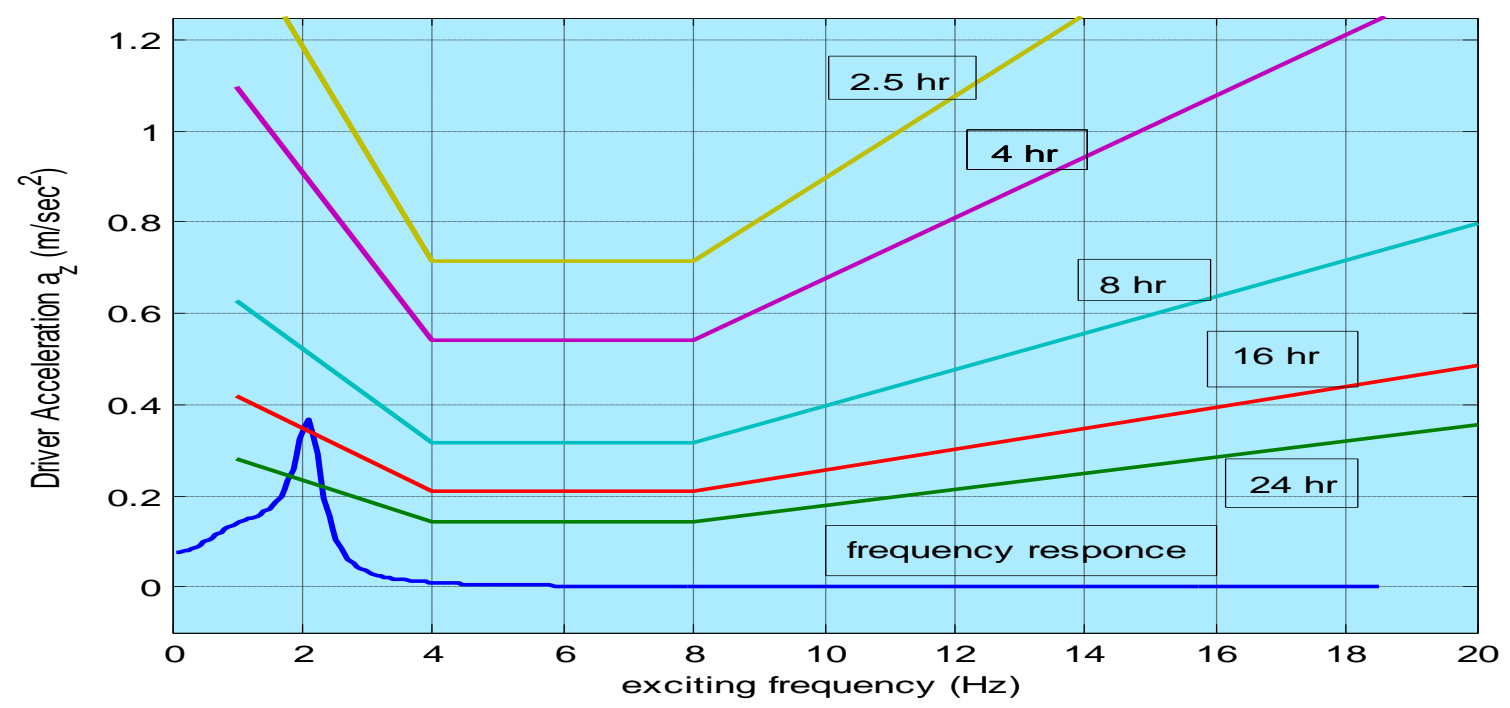

Figure (13): Driver bounces $\left(Z_{5}\right)$ acceleration rms and ISO2631 limits. 


\section{Conclusions:}

The mathematical model used in this research work can be used to study the dynamic system and simulation process to increase the efficiency of the system and reduce the effort which required in the design stage. The analysis of the previous physical model results for deriver and passengers vibration leads to compatibility with ISO 2631-1 for expose time from $1 \mathrm{~min}$ to $16 \mathrm{hr}$ for passengers. The vibration of the $24 \mathrm{hr}$ limit (for passengers ) and $16 \mathrm{hr}$ and $24 \mathrm{hrs}$ limits (for the driver) required the modification of the suspension system to avoid this problem and increase the comfort of the vehicle.

\section{References:}

[1] T.D. Gillespie, Fundamentals of Vehicle Dynamics, $6^{\text {th }}$ printing USA, Society Automotive Engineering SAE, Warrendale, 1992.

[2] N. J. Mansfield, Low Frequency Vibration Comfort, Loughborough University, Loughborough U.K. 2006

[3] I. Zeid, Simulation of Vibration in Automobiles, department of mechanical engineering, Northeastern University Boston, Massachusetts, 1988.

[4] J. C. Dixon, Tires, Suspension and Handling, $2^{\text {nd }}$ ed., USA, Society of Automotive Engineers, Warrendalle, 1996.

[5] B. Li ,M.E. Prac, 3-D Dynamic Modeling And Simulation Of A Multi-degree Of Freedom, M.Sc. Thesis, University Of Wollongong , 2006.

[6] K. Ogata. Modern Control Engineering, fourth edition, Pearson Prentice Hall, 2002

[7] Rahmi, Active Control of Seat Vibrations of a Vehicle Model Using Various

[8] Suspension Alternatives, Technical University, Faculty of Mechanical Engineering, Istanbul-TURKEY, 2001.

[9] N. A. Mohammed, G.A. Hassan, A Study Of A 10 Degrees Of Freedom Model For Vehicle Dynamics Response To Rod Hump, AEIC conference, El Azhar university, Cairo , Egypt. 2010.

[10] S. Rao, Mechanical Vibrations, Fourth Edition, Pearson Prentice Hall, 2004.

[11] C. M. Harris, A. G. Piersol, Shock and Vibration Handbook, fifth edition, McGrawHill, 2002.

[12] Occupational Health Clinic for Ontario Workers Inc. Whole Body Vibration, Toronto, Canada

[13] M.J. Griffin, Handbook of Human Vibration, University of Southampton, Academic Press, London, 1990

[14] Ann M. Nakashima, The Effect Of Vibration On Human Performance And Health, Defense R\&D Canada - Toronto, July 2004 